\title{
HIDRELÉTRICA DE BELO MONTE: DINÂMICA SOCIOESPACIAL DAS FAMÍLIAS NO RRC TRAVESSÃO 27 KM, VITÓRIA DO XINGU-PA
}

\author{
José Antônio Herrera ${ }^{1}$ \\ Nathany Melo Machado Arcanjo ${ }^{2}$ \\ Darlene Costa da Silva ${ }^{3}$
}

\begin{abstract}
RESUMO
Neste artigo apresentam-se as dinâmicas socioespaciais das famílias do Reassentamento Rural Coletivo (RRC) localizado no km 27 da BR 230 em Vitória do Xingu-PA. O mote está em discutir como os reassentados se organizam neste novo espaço agrário gerado pelo deslocamento compulsório das famílias diretamente impactadas com a construção da Usina Hidrelétrica de Belo Monte - UHBM. Partindo desta constatação, apresentou-se como resultado da pesquisa a necessidade de analisar a dinâmica socioespacial das famílias reassentadas do RRC que se dá de forma diversificada e oposta, para tal análise foram utilizados dados coletados em campo por meio de entrevistas com as famílias do RRC.
\end{abstract}

Palavras-chave: Belo Monte. Dinâmicas socioespaciais. Espaço agrário.

\begin{abstract}
This paper presents the socio-spatial dynamics of the families of the Collective Rural Resettlement (RRC) located at $27 \mathrm{~km}$ of BR 230, in Vitoria do Xingu - PA. The motto is to discuss how the resettled people are organized in this new agrarian space generated by the compulsory displacement of families directly impacted by the construction of the Belo Monte Hydroelectric Power Plant - UHBM. Based on this finding, it was presented as a result of the research, the need to analyze the socio-spatial dynamics of RRC resettled families that occur in diverse and opposite ways, for this analysis we used data collected in the field through interviews with families of the RRC. RRC.
\end{abstract}

Keywords: Belo Monte. Sociospatial dynamics. Agrarian space.

\footnotetext{
${ }^{1}$ Possui graduação em Licenciatura Plena Em Ciências Agrárias pela Universidade Federal do Pará (2001), graduação em Geografia pelo Centro Universitário de Araras Dr. Edmundo Ulson (2018), mestrado em Agriculturas Amazônicas pela Universidade Federal do Pará (2003) e doutorado em Desenvolvimento Econômico, Espaço e Meio Ambiente pela Universidade Estadual de Campinas (2012). Atualmente é professor Adjunto IV da Universidade Federal do Pará, na Faculdade de Geografia no Campus Universitário de Altamira e professor permanente no Programa de Pós-graduação em Geografia - PPGEO / IFCH / UFPA - Campus Universitário de Belém. Coordenador do Laboratório de Estudos das Dinâmicas Territoriais na Amazônia LEDTAM. Atualmente é Vice-Coordenador do Programa de Pós-Graduação em Geografia - PPGEO / IFCH / UFPA (Portaria 1972/2019). Tem experiência na área de Geografia, com ênfase em Geografia Humana, atuando principalmente nos seguintes temas: Amazônia, Território, Produção do Espaço; Grandes Projetos, Hidrelétricas; Relação Campo-Cidade. E-mail: herrera@ufpa.br

${ }^{2}$ É membra ativa do Grupo Desenvolvimento e Dinâmicas Territoriais na Amazônia GEDTAM e do Laboratório de Estudos das Dinâmicas Territoriais na Amazônia LEDTAM, pesquisadora voluntaria em: Rede de pesquisas Xingu - REDEX, Centro de Formação e Informação Xingu - CEFORM, Projeto de residência pedagógica e Fundação Amazônia de Amparo a Estudos e Pesquisas - Fapespa. E-mail: nathanymelo22@gmail.com

${ }^{3}$ Possui graduação em Geografia pela Universidade Federal do Pará (2013). Mestre em Geografia pela Universidade Federal do Pará/PPGEO (2016). Atualmente discente de doutorado - Universidade Federal de Rondônia (UNIR). Professora na área de Geografia Regional e Cartografia na Universidade Federal do Parál Campus de Altamira. Pesquisadora do grupo desenvolvimento e dinâmica territoriais na Amazônia GEDTAM e do Laboratório de Estudos das Dinâmicas Territoriais na Amazônia LEDTAM. E-mail: darlenesilva1@hotmail.com
} 


\section{INTRODUÇÃO}

A Amazônia, historicamente, sofre bruscas transformações em sua dinâmica local notadamente ocasionadas pelas ações dos agentes hegemônicos, como consequência da política de integração nacional e dos projetos desenvolvimentistas planejados pelos diferentes Governos do Brasil. No contexto das políticas desenvolvimentistas, sempre foram privilegiados os investimentos capitalistas e com eles a reprodução da valorização do capital em si mesmo, de forma a socializar os custos com a sociedade local à medida que os grandes conglomerados aumentam a concentração de riqueza e de poder.

Infelizmente, essa visão sobre Amazônia como espaço de exploração dos recursos naturais para o sistema capitalista atravessa décadas. Segundo Gonçalves (2001) “a região amazônica possui um enorme potencial de recursos naturais que estão suscetíveis a manipulações do governo e das grandes potências interessadas em explorá-la”. Assim, a Amazônia torna-se, de acordo com Santos (2006) "um território recurso - regido pelos interesses dos agentes exógenos em detrimento as lógicas e formas de reproduções locais território abrigo".

Os grandes projetos na Amazônia são planejados e pautados nas políticas neodesenvolvimentistas, afirmando assim um suposto desenvolvimento a partir da implantação de grandes obras como barragens, portos, estradas, aeroportos, mineração, entre outras. Portanto, tem-se a ideia de que para o desenvolvimento econômico no Brasil é necessário gerar energia para conseguir avançar de forma sustentável. No entanto, discursos como estes desconsideram a dinâmica socioespacial dos sujeitos locais, desconsideram a organização anterior do território e a sua regulação interna. Nestes termos, aproxima-se a realidade pesquisada com a afirmação feita por Santos (2006).

\footnotetext{
Antes o território continha o dinheiro, que era em parte regulado pelo dinheiro, pelo território usado. Hoje, sobe a influência do dinheiro, o conteúdo do território escapa a toda regulação interna, trazendo aos agentes um sentimento de instabilidade, essa produção sistemática do medo que é um dos produtos da globalização perversa dentro da qual vivemos, esse medo que paralisa, esse medo que nos convoca a apoiar aquilo que não cremos apenas pelo receio de perder ainda mais. (SANTOS $e t$ al. 2012 p. 19).
}

Os agentes endógenos modificam suas lógicas de reprodução, pelo contato com os agentes exógenos, os quais são condicionados a mudar a dinâmica dos seus costumes, das suas culturas e relações de produção, rompendo os laços com o antigo território e suas relações sociais e produtivas. 
Nesta perspectiva, propõe-se olhar para realidade das famílias deslocados compulsoriamente, obrigadas a se mover em função da construção da UHBM na Volta Grande do Xingu, para o Reassentamento Rural Coletivo (RRC) no Km 27 da BR 230, no município de Vitoria do Xingu. O qual foi organizado espacialmente pela Norte Energia desde as distribuições dos lotes para as famílias indenizadas entre os anos de 2015 e 2016 até as áreas de Preservação Permanente (APP) das quais as famílias do RRC não podem se apropriar dos recursos nelas existentes. Ao serem reassentadas as famílias passam a lidar com novas dinâmicas socioespaciais, distintas das dinâmicas anteriores às quais estavam habituadas, aquelas intrínsecas ao cotidiano.

\section{METODOLOGIA}

Serão retratados aqui os caminhos metodológicos adotados para realização da pesquisa. Tendo como base um conjunto de princípios, orientações e ações que, de forma articulada, permitem a aproximação da pesquisa com a realidade observada. Desse modo, descrevem-se os procedimentos metodológicos, as técnicas de obtenção e de análise de dados os quais foram obtidos através de idas a campo e entrevistas semiestruturadas com as 21 famílias do RRC.

\section{RESULTADOS E DISCUSSÕES}

O recorte espacial para análise em questão é o Reassentamento Rural Coletivo, localizado no Travessão 27 KM da rodovia Transamazônica (BR-230), munícipio de Vitória do Xingu-PA (Mapa 1), este é um projeto elaborado pela Norte Energia/S.A. como condicionante, proposta de compensação às famílias que moravam em áreas rurais impactadas pelo reservatório da UHE Belo Monte. 
Figura 1: Mapa de localização do RRC 27km - Vitória do Xingu-PA.

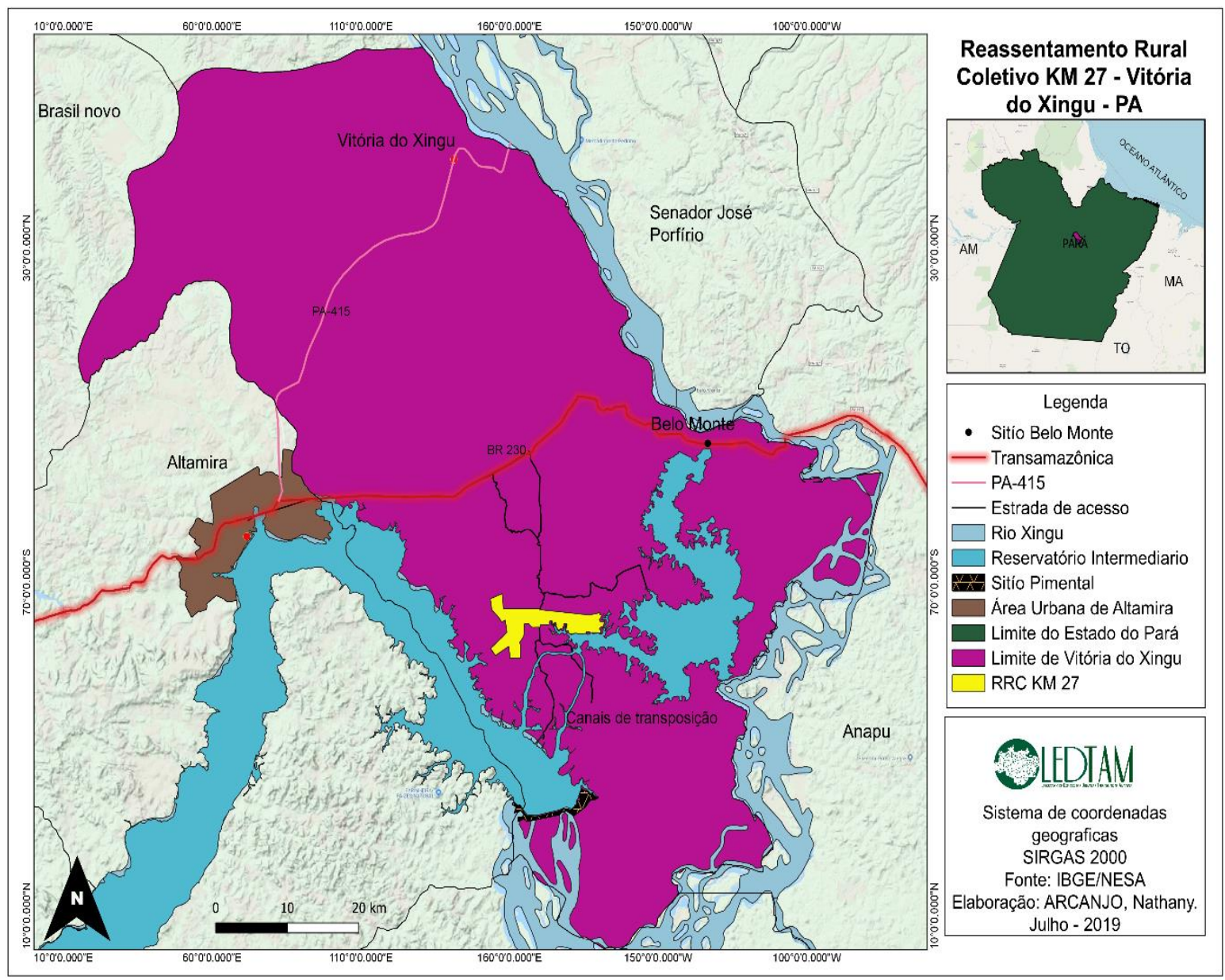

Fonte: Ledtam, 2018.

No entendimento da totalidade espacial em escala local, atenta-se para o apontamento feito por Santos (2012), para quem "nenhum enfoque que deixe de lado a noção de totalidade, permitirá uma correta noção da realidade". Deste modo, compreende-se que "com o desenvolvimento do capitalismo, as relações entre sociedade e seu espaço-suporte não mais têm caráter privilegiado, mas dependem de uma determinação externa que tem o domínio deste espaço, da orientação de sua produção e do destino de seus habitantes" (SANTOS, 2011, p. 138). Ainda nesta linha de raciocínio, corroborando com Santos (2012) tem-se como base de que "todas as partes de uma totalidade devem ser definidas pela ideia de forma, função processo e estrutura". Portanto, propomos um o quadro em síntese que revela as formas do RRC, sua atual função, os processos pelos quais o reassentamento se caracteriza e suas estruturas naturais e artificiais: 
Quadro 1: De síntese da forma, função, processo e estrutura do RRC.

\begin{tabular}{|c|l|}
\hline Forma & $\begin{array}{l}\text { Forma é o aspecto visível de uma coisa, no caso do RRC: Estruturados } \\
\text { com lotes de 75 hectares, casas de alvenaria bem estruturadas (com fossa } \\
\text { séptica, pisos lajotados, com três quartos, cozinha, banheiros) }\end{array}$ \\
\hline Função & $\begin{array}{l}\text { A função é a tarefa ou atividade de uma da forma, no caso do RRC, foi } \\
\text { vinculada às dinâmicas socioespaciais. }\end{array}$ \\
\hline Processo & $\begin{array}{l}\text { São as relações com o meio que são concretizadas no tempo e no espaço, } \\
\text { no caso do RRC concretizam-se essas relações a partir do momento de sua } \\
\text { formação em 2015 e, posteriormente, se firmando uma possibilidade de } \\
\text { compreensão evolutiva da organização espacial nos anos 2016, 2017 e } \\
\text { 2018. }\end{array}$ \\
\hline Estrutura & $\begin{array}{l}\text { A estrutura é aquilo que está subjacente à forma, ou seja, as formas } \\
\text { naturais e artificiais que possibilitaram a formação espacial do RRC. }\end{array}$ \\
\hline
\end{tabular}

Fonte: Moreira (2016). Adaptação Arcanjo, (2018).

De tal maneira, define-se como central na interpretação a definição de dinâmica socioespacial, esta entendida como desdobramento do que Santos (2006) considerou ao propor a Dimensão Espacial do Cotidiano. E por isso, destaca-se que:

\footnotetext{
Com o papel que a informação e a comunicação alcançaram em todos os aspectos da vida social, o cotidiano de todas as pessoas assim se enriquece de novas dimensões. Entre estas, ganha relevo a sua dimensão espacial, ao mesmo tempo e que esse cotidiano enriquecido se impõe como uma espécie de quinta dimensão do espaço banal (SANTOS, 2006, p. 217).
}

Portanto, tem-se a compreensão da dinâmica socioespacial, analisando as transformações do espaço (o RRC), valorizando a importância dos sujeitos locais, ao passo em que registra a (re)estruturação das famílias reassentadas. Entendendo que "O espaço inclui, pois, essa conexão materialística de um homem com o outro" de que falavam Marx e Engels na Ideologia Alemã (1947, pp. 18-19), conexão que está sempre tomando novas formas. Assim, tem-se como balizar para compreender a dinâmica socioespacial que a relação geográfica mais simples, a relação homem/natureza, é "cada vez menos determinada pelas características da área e pelo processo direto de produção, e cada vez mais um resultado do processo de organização da produção vista como um todo" (SANTOS, 2006, p. 97). 
A hidrelétrica de Belo Monte é um projeto energético brasileiro implantado na volta grande do rio Xingu no sudoeste do estado do Pará, com uma produção estimada de pouco mais de 11 mil megawatts, tornando-se a segunda maior hidrelétrica do Brasil, ficando atrás apenas da usina de Itaipu. Nessa lógica capitalista de expansão hidroelétrica na região, são geradas novas dinâmicas locais, desde a sua especulação e licenciamento prévio em 2010 quanto em 2011 com o início das obras.

Os impactos socioespaciais causados nas áreas afetadas pela construção da UHE Belo Monte, são atribuídos às ações do Governo Federal e ao consórcio construtor Norte Energia / S.A., empresa responsável pela construção da obra. No entanto, para a evolução da construção da usina hidroelétrica foram necessárias a criação de medidas reparadoras desses impactos causados pelo empreendimento. As condicionantes e medidas mitigadoras são formas "compensatórias" oferecidas às famílias das áreas afetadas como forma de ressarcimento financeiro de suas áreas atingidas, com a carta de crédito ou com o reassentamento em áreas rurais pré-determinadas pelo empreendimento, como o RRC, RAR, RIR ou PER. ${ }^{4}$

No caso do objeto de pesquisa, o RRC, um projeto elaborado pela Norte Energia/S.A. em 2015, construído após o início e andamento da construção da hidrelétrica de Belo monte, surgiu como forma compensatória e reparadora dos impactos causados nas áreas onde residiam as famílias da Volta Grande do Xingu. No RRC foram construídas casas e infraestrutura básica ocupando uma área total acima de 2,4 mil hectares sendo divididos em áreas com:

Quadro 2: Distribuição das áreas do Reassentamento Rural Coletivo

\begin{tabular}{|l|l|}
\hline \multicolumn{1}{|c|}{ ESTRUTURAS } & ÁREA (ha) \\
\hline Área Total do Projeto & 2474,64 \\
\hline Área de Reserva Legal (ARL) & $1.770,66$ \\
\hline Área de Preservação Permanente (APPs) & 194,56 \\
\hline $\begin{array}{l}\text { Área dos Lotes (AUAS) - 28 áreas com, aproximadamente, 15 ha cada - } \\
\text { vide Quadro 4.1.3 - 2 }\end{array}$ & 440,454 \\
\hline Área do Centro Comunitário & 3,0957 \\
\hline
\end{tabular}

\footnotetext{
${ }^{4}$ O Projeto de Indenização e Aquisição de Terras e Benfeitorias cumpriu com seus objetivos ao viabilizar o processo de indenização em áreas rurais interferidas pelo empreendimento. As questões sobre reassentamento rural, tratadas por quatro projetos no Programa de Negociação e Aquisição de Terras e Benfeitorias na Área Rural, tratadas pelo Projeto de Reassentamento Rural (4.1.3), como o Reassentamento Rural Coletivo (RRC), o Reassentamento em Áreas Remanescentes (RAR) e a população ribeirinha. Em relação a este último grupo, foram feitas ofertas para relocação das famílias ribeirinhas em ilhas emergentes (RIR) ou em porções emersas remanescentes (PER).
} 


\begin{tabular}{|l|l|} 
Área do IBAMA & 3,02 \\
\hline Área da Serraria & 6,5798 \\
\hline Reserva Técnica (Norte Energia) & 29,1419 \\
\hline Estradas & 4,23 \\
\hline Sítios Arqueológicos & 22,9 \\
\hline
\end{tabular}

Fonte: Apresentação Ministério Público do Estado do Pará. Norte Energia.

Foram reassentadas 28 famílias entre os anos de 2015 e 2016. Os lotes de 75 hectares foram divididos em 15 hectares para uso agrícola e 60 hectares para a reserva legal, é possível observar no mapa 02 a distribuição espacial dos lotes e das estruturas dentro do reassentamento.

Figura 2: mapa de distribuição espacial dos lotes no RRC.

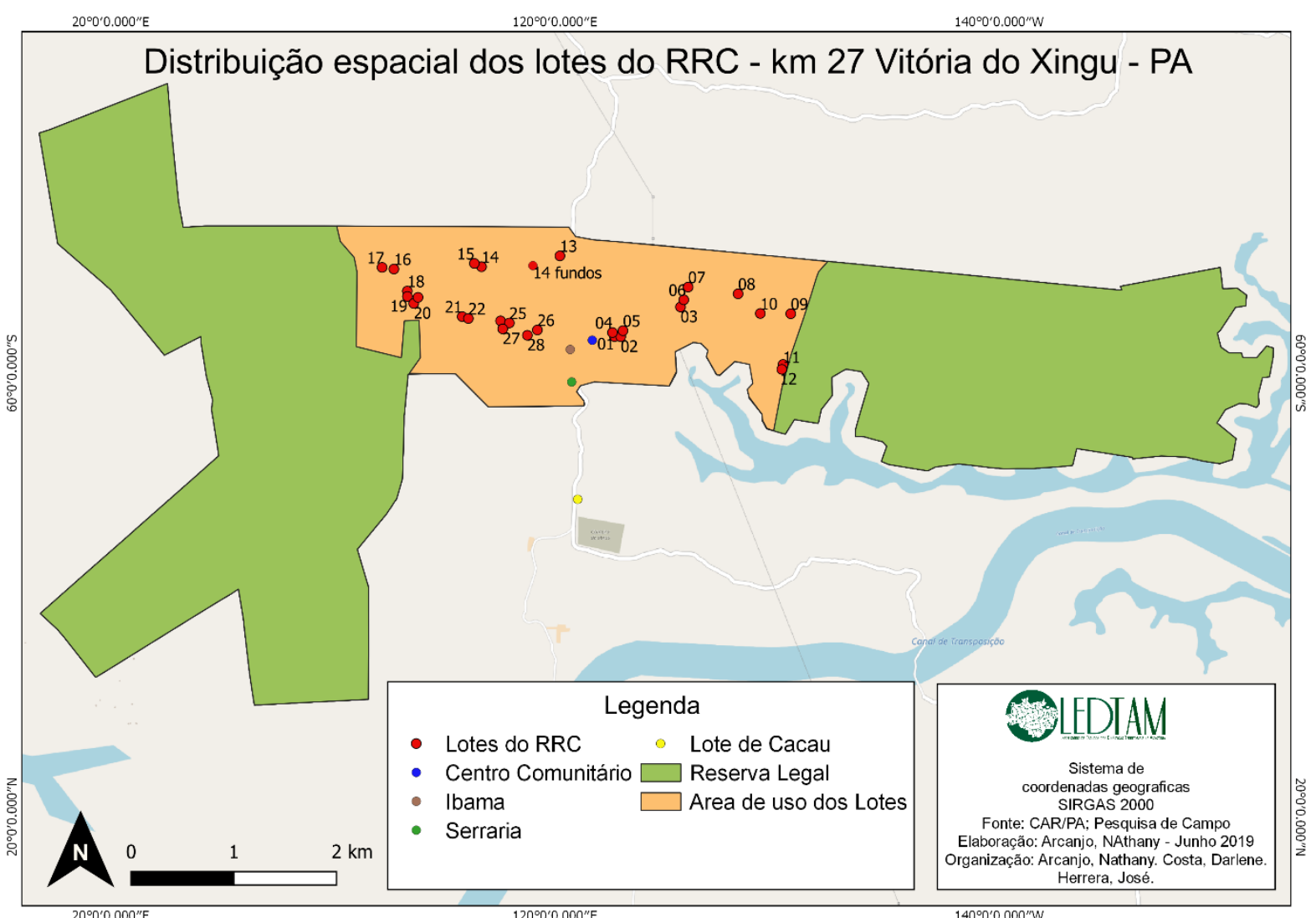

Fonte: Ledtam, 2018. 
Os lotes de 75 hectares foram distribuídos para cada uma das 28 famílias atingidas. Além dos lotes individuais foram disponibilizadas áreas para as reuniões do RRC, que acontecem no galpão comunitário e um campo de futebol como área de lazer.

Sendo assim, entende-se este território como consequência da organização e produção do espaço a partir da lógica do empreendimento, sendo (re)configurado pelas novas dinâmicas socioespaciais dos sujeitos do RRC. A (re)organização dos reassentados nos lotes, condicionados pelo empreendedor, em tempos distintos e de maneira desigual, provocou a (re)funcionalização do território. Notadamente, o reassentamento tem sido (re)funcionalizado, à medida que as famílias remanejadas do entorno do reservatório da hidrelétrica e as famílias não remanejadas produzem o espaço a partir das suas relações sociais e produtivas.

As casas construídas no RRC, possuem três quartos, cozinha com sala e banheiros adaptados para pessoas com deficiência, fossa séptica, rede de energia elétrica, poço artesiano e vias de acesso. Importante destacar que a infraestrutura estabelecida é uma tentativa de minimizar os descontentamentos das famílias retiradas compulsoriamente dos seus lugares de origem e uma forma direta de tentativa de sociabilidade e ressignificação socioespacial.

Figura 03: Casa do RRC, estrutura da Norte Energia.

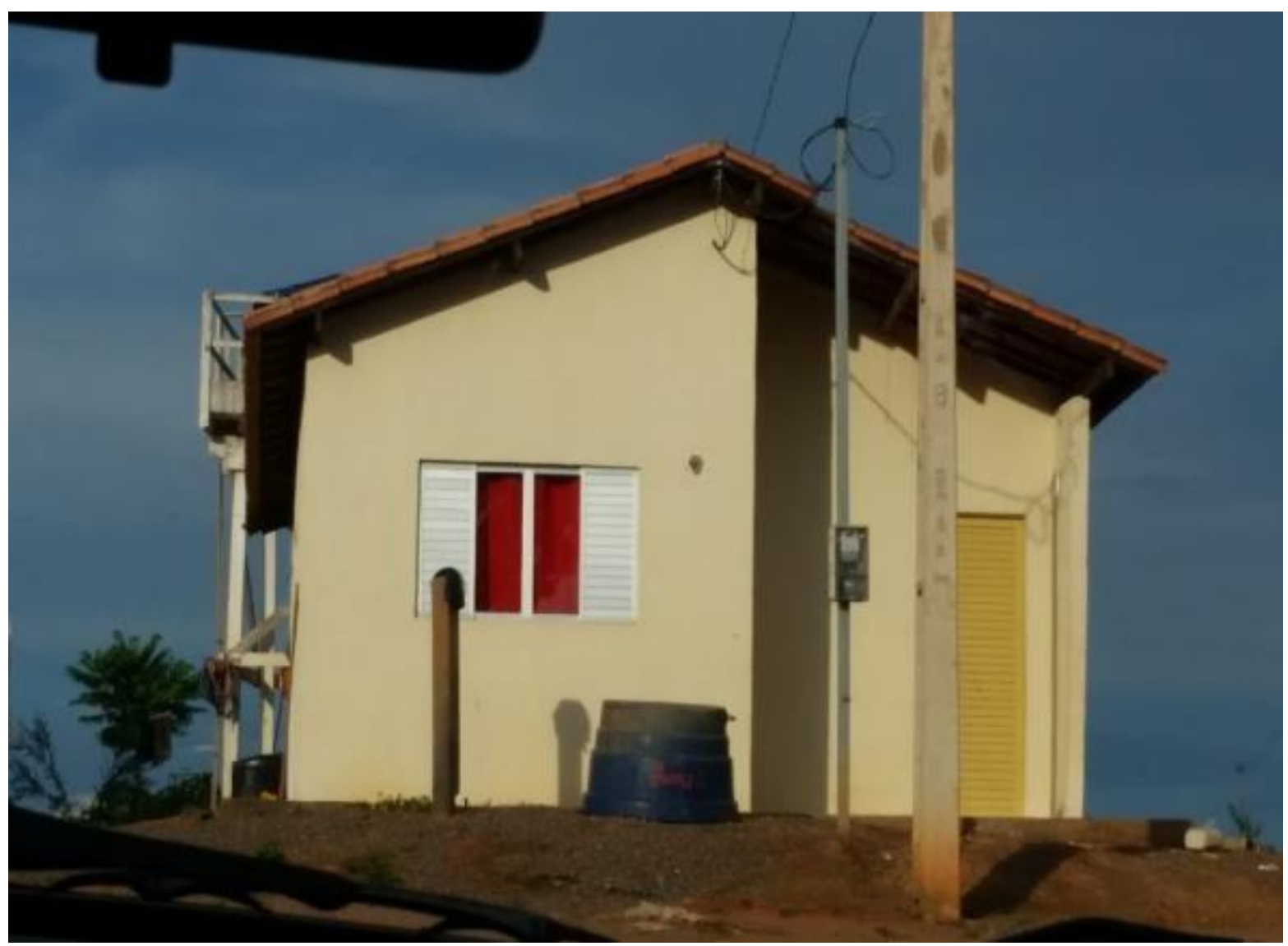

Fonte: Ledtam, 2017, Nathany Melo M. Arcanjo. 
No entanto, com os resultados da pesquisa quanto ao atendimento das condicionantes geradas pelo empreendimento Belo Monte, evidenciou-se que as famílias foram reassentadas em uma área distinta, com condições bem diferentes das antes vividas, estas tiveram formas diferenciadas de estabelecer relações com o novo espaço. As famílias que vieram do entorno do rio tendem a reproduzir as formas tidas no antigo território, como é o caso de algumas famílias reassentadas como pode-se observar nas figuras 04 e 05.

Figura 04: Casa adaptada pelas famílias realocadas.

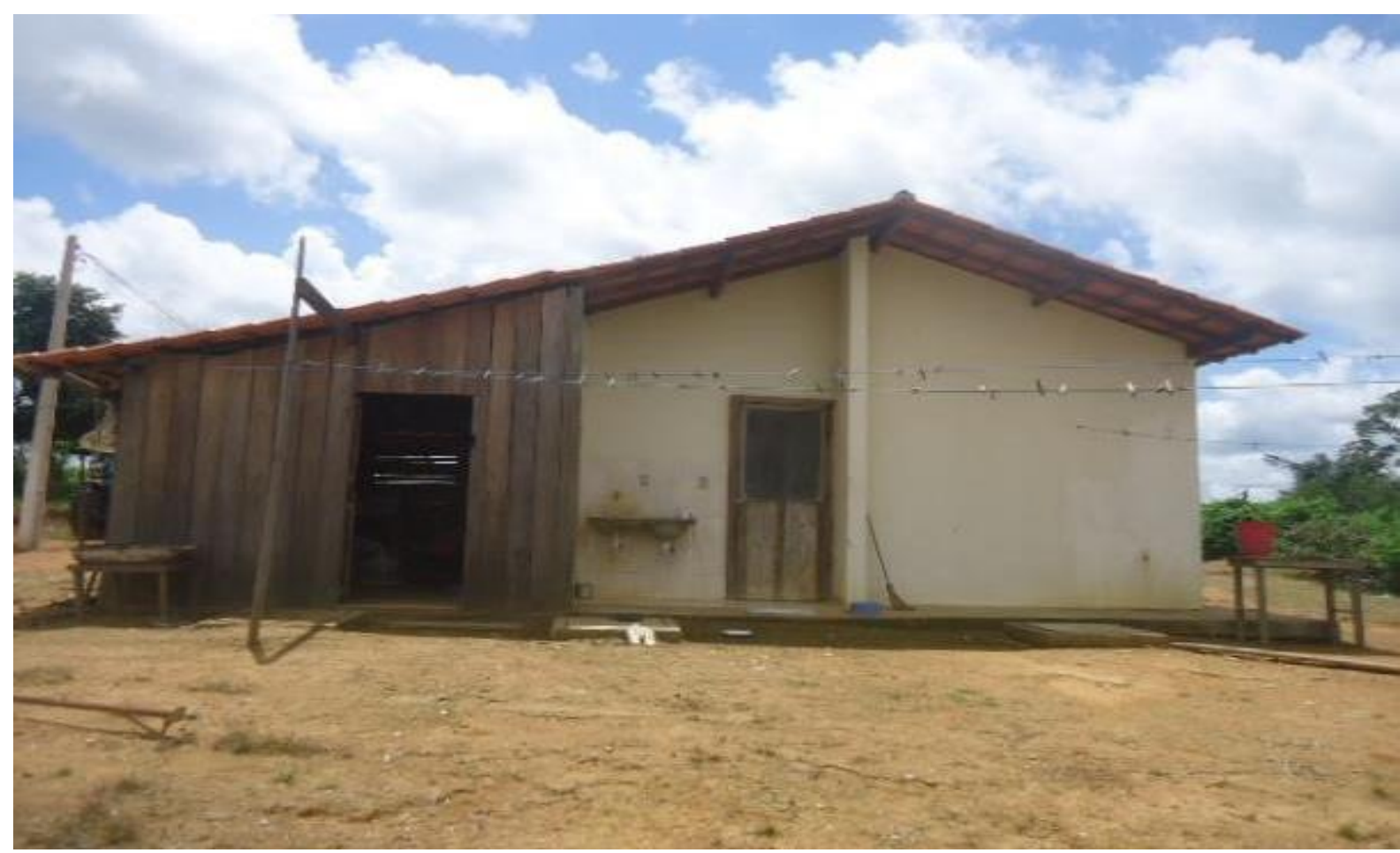

Fonte: Ledtam, 2017. Nathany Melo M. Arcanjo 
Figura 05: Casas adaptadas, parte interna.

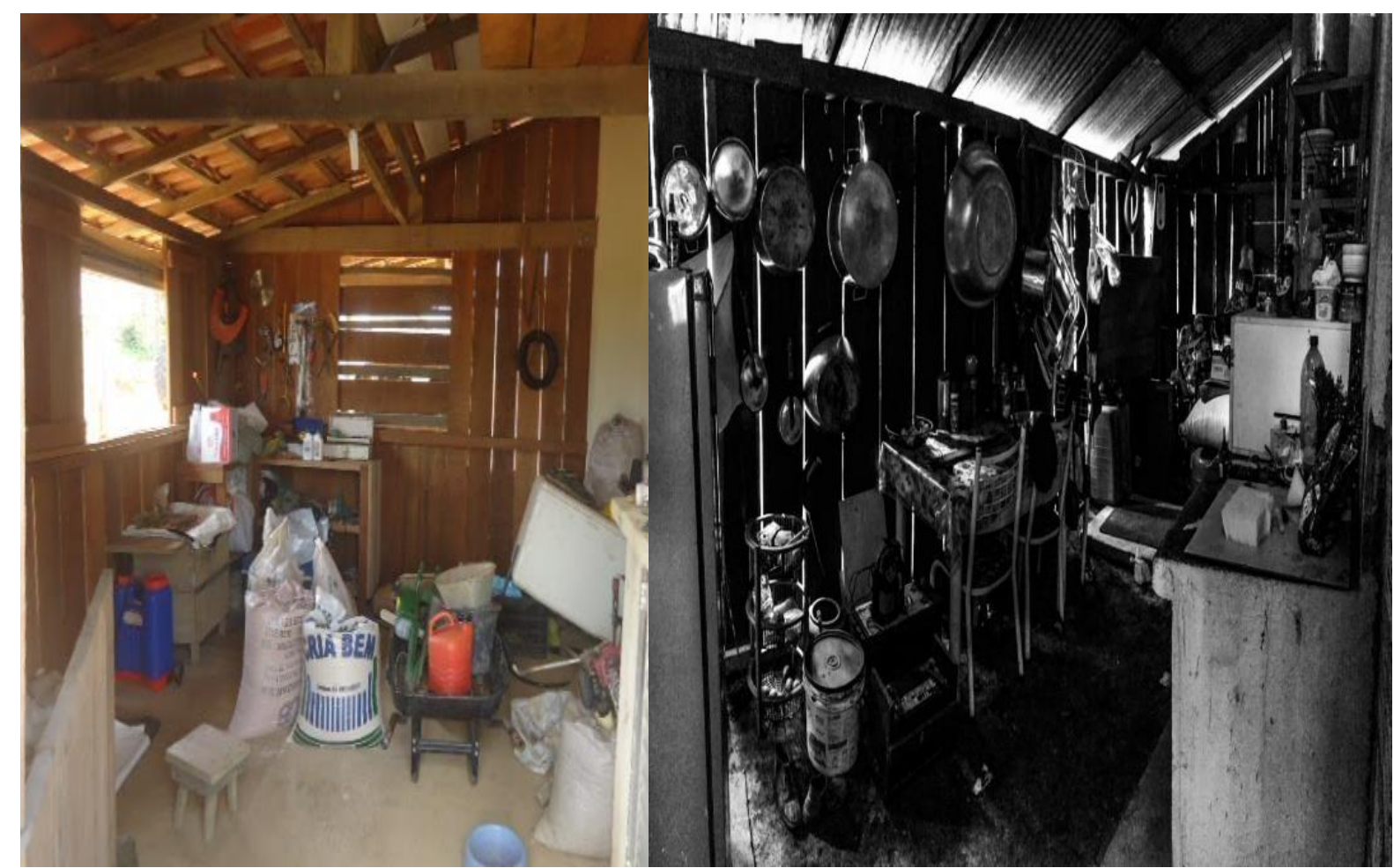

Fonte: Ledtam, 2017. Nathany Melo M. Arcanjo

O ritmo do cotidiano vivenciado pelas famílias no território anterior ao RRC estava conectado diretamente com um território vivido, onde ocorriam as relações com o trabalho na terra e no rio, as relações culturais e sociais, ou seja, havia uma organização espacial das famílias antes do empreendimento energético se instalar. Após a instalação houve-se a necessidade, atribuída ao evento de Belo Monte, de reorganizar o espaço para reassentar as famílias que estavam nas áreas afetadas pelo empreendimento. Legitimando a afirmação de Santos (2006), “as atividades hegemônicas exigem a renovação do espaço construído”.

Algumas famílias tiveram êxitos nas relações com o meio, diferente de outras que não desenvolveram relações de elo com o território, chegando ao ponto de venderem ou até mesmo abandonarem seus lotes por não saberem lidar com o as novas dinâmicas socioespaciais. Como podemos observar no gráfico 01 houve uma evasão de uma parcela das pessoas reassentadas, dando, assim, lugar a chegada de novas famílias ao RRC. 
Gráfico 01: Espacialização das famílias no RRC.

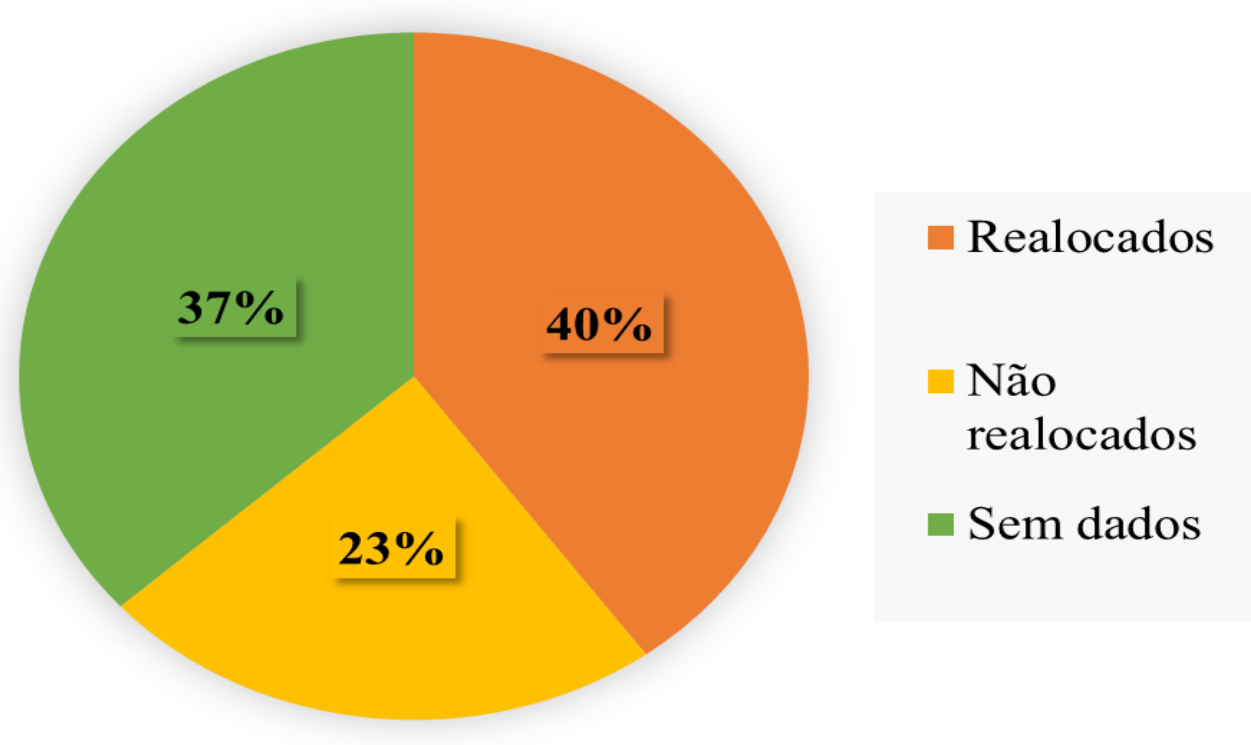

Fonte: Ledtam, 2017. Nathany Melo M. Arcanjo

O Reassentamento Rural Coletivo do km 27 de Vitória do Xingu-PA, assim como outras formas de indenização, é para os agentes hegemônicos apenas uma ação compensatória para as famílias diretamente afetadas por hidrelétricas na Amazônia. Portanto, compreendemos que o RRC é um projeto que deveria ser pensado mais humanamente, tendo em vista as dificuldades pelas quais as famílias enfrentaram para chegar ao novo território e enfrentam para se manterem e para se (re)organizarem nele.

A formação social e econômica atual, caracterizada pelo modo capitalista de produção que atinge todas as esferas sociais e transforma o espaço de acordo com suas necessidades, tem suas bases em contradições que se atualizam permanentemente, renovando assim as formas de acumulação. A subordinação do capital sob o trabalho, baseada na expropriação dos meios de vida de um grupo da população, busca o crescimento econômico e a expansão como condição inerente ao mesmo, expressado paralelamente em graus de degradação e desigualdade em termos sociais, ambientais e culturais (Gómez, Souza, p.69, 2016).

Ou seja, os processos de (re)configuração desse novo território acontece de forma desigual entre as diversas famílias reassentadas, algumas possuíam um maior conhecimento técnico e, portanto, conseguiram se desenvolver mais "facilmente", no entanto a realidade para outros lotes é divergente dos lotes desenvolvidos, pois os mesmos não tinham tanto conhecimento com agricultura ou com o tanque de peixes, isso fez com que alguns 
abandonassem a produção agrícola familiar e buscassem novas estratégias econômicas. Como podemos ver no gráfico 02 .

Gráfico 02: Representatividade das atividades na renda familiar dos entrevistados.

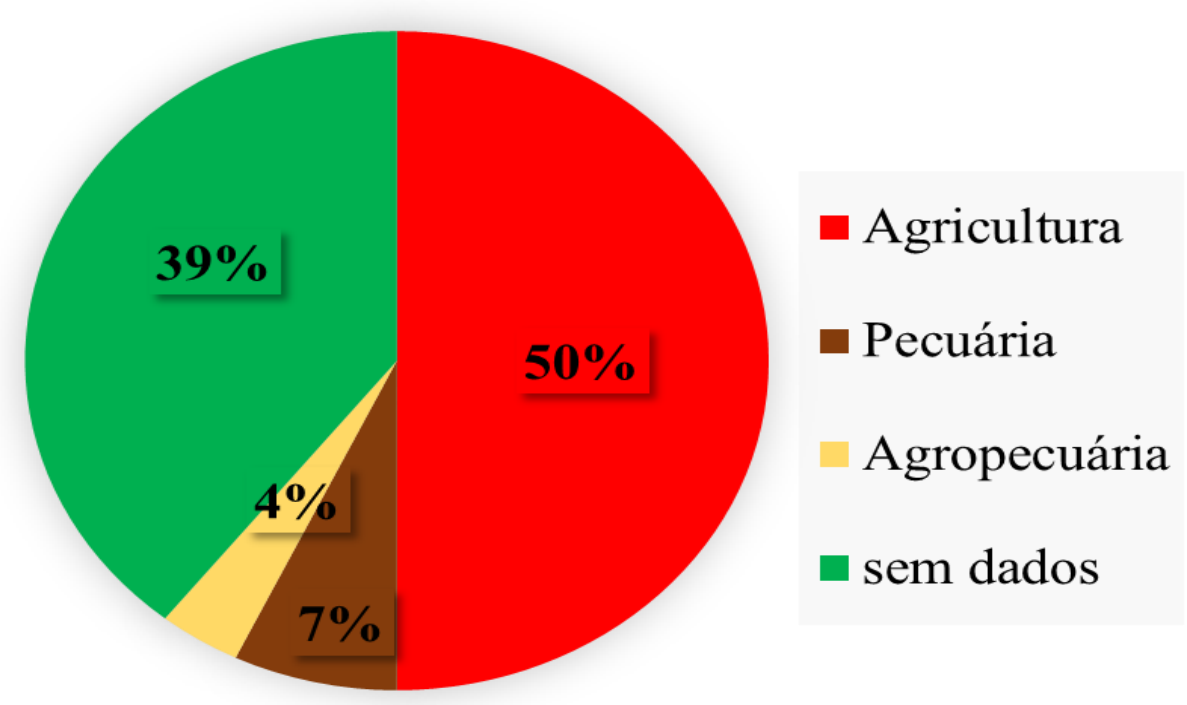

Fonte: Ledtam, 2017. Nathany Melo M. Arcanjo

Há uma reorganização da dinâmica do território local, dos sujeitos locais. Isso implica para as famílias reassentadas novas formas de se reorganizar, reestruturar socialmente e economicamente, novas dinâmicas socioespaciais.

$\mathrm{O}$ fato do RRC ser uma antiga fazenda e nem todos terem habilidades com a terra ou com o tanque de peixes, implicou em uma parcela dos reassentados que não conseguiram de fato se reorganizar no novo território, enfrentando as dificuldades de uma terra diferenciada com a qual não estavam habituados, um território com diversas temporalidades. Corroborando com aquilo que Santos (2006) conceitua como um "conjunto indissociável, solidário e também contraditório, de sistemas de objetos e sistemas de ações, não considerados isoladamente, mas como um quadro único no qual a história se dá”. Portanto, no RRC há resquícios de outro período o qual implica na evolução das funções de algumas famílias que buscaram novas estratégias para desenvolverem-se socioespacialmente.

Tendo em vista que todos os meios de produção foram fornecidos pela empresa terceirizada pela Norte Energia, Equilíbrio, a mesma deveria ter analisado a condição de cada família e pensado em estratégias diferenciadas para cada uma delas. 
A generalização dos modos de vidas das famílias, escamoteou a realidade. Nem todos tinham conhecimentos sobre o uso do solo ou os procedimentos para manter e desenvolver um tanque de peixe. Minimamente deveriam respeitar ou apresentar estratégias para o novo modo de vida de todas as famílias, já que a manutenção de vida das mesmas partes de um mesmo espaço geográfico o que, no entanto, se particulariza a partir de como cada uma das famílias se relaciona com o novo território.

Outra questão de suma importância a ser considerada é em relação à construção das identidades nos novos territórios, algumas famílias ainda não se sentem pertencentes a este novo espaço tão próximo e distante do rio ao mesmo tempo. Estamos diante de um processo em andamento no RRC, as famílias ali reassentadas passam por constantes transformações intrínsecas deste espaço. Ali elas se veem induzidas a se adaptarem à nova dinâmica, entendemos como uma readaptação dos seus antigos modos de vida para este novo espaço geográfico, assim como também buscam novas estratégias para sua (re)produção existencial no reassentamento. Sendo assim, o estudo no RRC se dá juntamente com a evolução das dinâmicas socioespaciais intrínsecas deste espaço.

\section{CONCLUSÕES}

Ao passo em que grandes projetos se instalam em determinadas localidades, há uma desorganização dos costumes cotidianos das famílias locais, a UHE Belo Monte impôs novas dinâmicas socioespaciais para as famílias do RRC. Ao reorganizar um espaço desconhecido para as famílias afetadas pelo empreendimento, buscou-se, pelas mesmas, novos meios de se organizarem, novas estratégias, novas formas de se relacionarem com o meio. Houve a necessidade de se recriarem em um novo território, no qual ainda não há laços de ligação firmes o suficiente, pois algumas famílias que não conseguiram lidar com as novas dinâmicas socioespaciais partiram para novos territórios em busca de se reorganizarem em territórios novos, porém mais parecidos com o antigo território abrigo. 


\section{REFERÊNCIAS}

ARCANJO, Nathany Melo Machado. COSTA, Darlene Silva Da, HERRERA, José Antônio. Hidrelétrica Belo Monte: Reestruturação Social e Econômica dos Reassentados Do RRC/Travessão 27- Vitória Do Xingu /Pa. VIII Simpósio Internacional de Geografia Agrária e IX Simpósio Nacional de Geografia Agrária. ISNN 1980- 4555. Nov. 2017

BECKER, Bertha K. Significância contemporânea da fronteira: Uma interpretação geopolítica a partir da Amazônia brasileira. In AUBERTIN, C (ed.). Fronteiras1988. Brasília: Universidade de Brasília (UNB) / ORSTOM 1988b. p. 60-89.

GONÇALVES. Carlos Walter Porto. Amazônia, Amazônias. São Paulo: Contexto, 2001.

GONÇALVES. Carlos Walter Porto. Amazônia: Encruzilhadas civilizatória: Tensões territoriais em curso. Rio de Janeiro: Consequência Editora, 2017.

GÓMEZ, Mónica Castañeda. SOUZA, Wilma Gomes. Grandes empreendimentos, valorização do capital e transformações rural-urbano. Revista. Rural \& Urbano, Recife. v. 01, n. 01, p. 67-74, 2016. monik8705@yahoo.com.mx/wilmmasouza @ gmail.com Universidade Federal de Pernambuco.

HERRERA, José Antônio. Desenvolvimento capitalista e a produção do espaço agrário amazônico - Geosul, Florianópolis, v. 34, n. 71- Dossiê Agronegócios no Brasil, p. 473-499, abril. 2019. Disponível em: http://doi.org/10.5007/1982- 153.2019v34n71p473. Acesso em: set. 2018

HERRERA, José Antônio. NETO, José Queiroz de Miranda. MOREIRA, Rodolfo Pragana. Integração e estruturação do território amazônico como consequência da expansão capitalista no Brasil. Maringá, v. 31, n. 2, p. 19-36, maio-ago. 2013. Disponível em: https://www.researchgate.net/publication/276294994_INTEGRACAO_E_ESTRUTURACAO _DO_TERRITORIO_AMAZONICO_COMO_CONSEQUENCIA_DA_EXPANSAO_CAPI TALISTA_NO_BRASIL_Integration_and_structure_of_the_amazonian_territory_as_a_result _of_capitalist_expansion_in_Brazil. Acesso em: 22 març.2019.

HERRERA, José Antônio. MOREIRA, Rodolfo Pragana. BEZERRA, Tássia Stêfany Lima. A Amazônia: Expansão do capital e apropriação dos recursos naturais. Revista Brasileira de Gestão e Desenvolvimento Regional. G\&DR . v. 12, n. 2, p. 208-227, mai-ago/2016, Taubaté, SP, Brasil.

HERRERA, José Antônio. A estrangeirização de terras na amazônia legal brasileira entre os anos 2003 e 2014. CAMPO- TERRITÓRIO: Revista de geografia agrária. Edição especial, p. 136-164, jun., 2016

MARX, KARL, 1818-1883: A ideologia alemã / Karl Marx e Friedrich Engels; [introdução de Jacob Gorender]: Trad. Luís Claudio de Castro e Costa - São Paulo: Martins Fontes, 1998.

MOREIRA, Rodolfo Pragana. Desterritorialização do Baixão do Tufi: Da formação espacial aos novos Reassentamentos Urbanos Coletivos (RUCs) em Altamira/PA. Dissertação (Mestrado em Geografia), Belém do Pará, 2018. 
QUEIROZ, Thiago Augusto Nogueira de. Espaço Geográfico, Território usado e lugar: Ensaio sobre o pensamento de Milton Santos. 8 (2): 154-161, ago. /dez. 2014. Universidade Federal do Rio Grande do Sul, Instituto de Geociências, Programa de Pós-Graduação em Geografia, Porto Alegre, RS, Brasil ISSN 1982-0003. Mestre em Geografia - UFRN. IFRN. 2015. Versão online publicada em 13 jan. 2016. Disponível em: Http://seer.ufrgs.br/paraonde. Acesso em: julh. 2018

ROCHA, Humberto José Da. O controle do espaço tempo nos processos de instalação de hidrelétricas. Junho 2014, p. 259-280.

SANTOS, Milton, Laura Silveira, Maria. O Brasil: Território e sociedade no início do século XXI. ISBN 850-10-59-39-0 - 9 ed. - Rio de Janeiro: Record, 2006.

SANTOS, Milton. Da Totalidade ao Lugar. São Paulo: Editora da Universidade de São Paulo, 2012. ISBN 978-85-314-0882-3. Território, Territórios: ensaio sobre o ordenamento territorial, . 3. Ed. ISBN 978- 8598271-42-2. - Rio de Janeiro: Lamparina, 2011.

SANTOS, Milton. A Natureza do espaço: Técnica e Tempo Razão e Emoção. - 4 ed. 2, reimpr. ISBN 85314-0713-3 - São Paulo: Editora da Universidade de São Paulo, 2006.

SANTOS, Milton. Espaço e Método. 5. Ed. 2 reimpr. ISBN 978-85-314-1085-7.

- São Paulo: Editora da Universidade de São Paulo, 2014.

SOUZA, César Martins de. Memórias da ditadura nas memórias da Transamazônica (19701990). Universidade Federal do Pará. email:cesar@ufpa.br. Disponível em: https://seminariomemoriatraumaereparacao.

weebly.com/uploads/1/4/8/8/14881944/souza_csar_martins.pdf. Acesso em: 19 julh 2018.

UHE BELO Monte Perguntas e Respostas. Secretaria de Comunicação Social/PR - UHE

Belo Monte Perguntas e Respostas. http://www.mma.gov.br/estruturas/182/_arq uivos/faq_belomonte_182.pdf. Acesso em: 22 març. 2019.

Recebido em: 22/10/2019

Aprovado em: 23/11/2019 